\title{
Eletroacupuntura aplicada nas fases precoce e tardia da cicatrização do tendão calcanear comum de coelhos após reparo tardio com peritônio bovino conservado em solução supersaturada de sal: aspectos clínicos
}

\author{
Effects of eletroacupuncture on acute and chronic rabbit acchiles tendon healing, after late \\ reconstruction using salt supersatured - stored bovine peritoneum graft: clinical aspects \\ Patricia Maria Coletto Freitas ${ }^{1}$ Carlos Roberto Daleck ${ }^{2}$ Mariana da Silva Melo \\ Duvaldo Eurides $^{3}$ Sebastião Martins Filho ${ }^{4}$ Letícia Binda Baungarten ${ }^{4}$
}

\section{RESUMO}

\begin{abstract}
Para avaliar o uso da eletroacupuntura (EA) sobre os aspectos clínicos e deambulatórios, 36 coelhos tiveram o tendão calcanear comum seccionado e, após 30 dias, receberam enxerto de peritônio bovino conservado em solução supersaturada de sal. Em seguida, os animais foram distribuídos aleatoriamente em três grupos de igual número: no primeiro grupo, os coelhos foram estimulados pela EA do segundo ao $11^{\circ}$ dia de pós-operatório (PO) (E10); no segundo grupo do $11^{\circ}$ ao $31^{\circ}$ dia de PO (E20) e, no terceiro grupo, os animais não foram estimulados (C). Verificou-se, nos animais do E10, durante o PO, ausência de edema e hiperemia no membro tratado pela EA. Não se observou diferença significativa $(P>0,05)$ entre os grupos quanto ao grau de deambulação dos animais. Todos os coelhos tiveram completa recuperação da deambulação até os 51 dias de PO. A utilização da eletroacupuntura na fase precoce da cicatrização do tendão calcanear comum de coelhos impediu a formação de edema e hiperemia. $O$ tratamento com eletroacupuntura no $P O$ não melhorou o desempenho da deambulação.
\end{abstract}

Palavras-chave: eletroacupuntura, enxerto, tendão, coelho.

\section{ABSTRACT}

In order to evaluate the use of eletroacupuncture (EA) on clinical and functional aspects, the Acchiles tendon of thirty-two rabbits was sectioned and after 30 days was grafted using salt supersatured - stored bovine peritoneum graft. Then, animals were distributed into three equally groups. They were stimulated by EA from the second to $11^{\text {th }}$ post - operative day (S10 group), from $11^{\text {th }}$ to $31^{\text {th }}$ pos-operative day (S20 group), or were not stimulated (C group). Neither edema nor hyperemia were detected on $\mathrm{S} 10$ animals. There were no significant $(P>0.05)$ differences between groups related to functional aspects. All rabbits were recovered until the 51th day of the post-operative period. The use of eletroacupuncture on acute Acchiles tendon healing avoided edema and hyperemia, but did not improve functional aspects.

Key words: eletroacupuncture, graft, tendon, rabbits.

\section{INTRODUÇÃO}

A ruptura do tendão calcanear comum é a lesão tendínea mais freqüentemente observada na rotina clínico-cirúrgica de animais de companhia (COSTA NETO et al., 1999). Esta lesão geralmente é decorrente de traumatismos, devido à ação de objetos cortantes ou agudos, ou lacerações associadas a acidentes de automóveis (CLARCK, 1993). Quanto ao tempo, a tenorrafia pode ser primária, primária protelada, secundária e secundária protelada. A reparação primária é realizada em 12 horas após a ruptura, a primária protelada em até 10 a 14 dias, a secundária é feita após o período de 14 dias e a secundária protelada após quatro semanas (RAISER et al., 2001). Nos casos de ruptura tendínea crônica, após trinta dias da lesão, a reconstrução torna-se difícil, devido à retração das extremidades tendíneas e presença de um tecido de cicatrização extenso no local da ruptura (ARON, 1996). Nesses casos, segundo WANG (1998), a reparação do tendão pode requerer o uso de enxerto. Assim, várias

'Programa de Doutorado em Cirurgia Veterinária, Universidade Estadual Paulista (UNESP), Jaboticabal. Centro de Ciências Agrárias (CCA), Universidade Federal do Espírito Santo (UFES). E-mail: pcoletto@yahoo.com.br. End.: Alto Universitário, s/n, CP 16, 29500-000, Centro, Alegre, ES, Brasil. Autor para correspondência.

${ }^{2}$ Departamento de Clínica e Cirurgia, UNESP, Jaboticabal, SP, Brasil.

${ }^{3}$ Faculdade de Medicina Veterinária (FAMEV), Universidade Federal de Uberlândia (UFU), Uberlândia, MG, Brasil.

${ }^{4}$ Centro de Ciências Agrárias, Alegre, ES, Brasil. 
pesquisas têm sido desenvolvidas no sentido de encontrar um material que seja adequado para reparação de tendão lesado. As membranas biológicas, devido a sua fácil obtenção, conservação e custo reduzido, surgiram nos últimos anos como uma alternativa de material destinado a enxertos. RAISER et al. (2001) usaram tendão de cães e COSTA NETO et al. (1999) empregaram peritônio de bovino, ambos conservados em glicerina a 98\%, para reparação de tendão calcanear comum em cães. Entretanto, a sobrevivência de um enxerto depende de sua adequada nutrição. Como os tendões são avasculares e seu suprimento sanguíneo é oriundo do paratendão, da junção músculo-tendínea e ósteo-tendínea (PAYNE \& TOMLINSOM, 1993), enxertos neste local têm sua sobrevivência dependente de tecidos adjacentes (MADDEN, 1970). Assim, na tentativa de acelerar processos reparativos e regenerativos, têm sido utilizados no pós-operatório de diversas cirurgias os chamados adjuvantes da cicatrização (RAISER et al., 2001). Entre eles, encontram-se o laser, o ultra-som terapêutico, a estimulação elétrica transcutânea (TENS) e a eletroacupuntura (EA) (JANSEN et al., 1989, GUM et al., 1997). A terapia por EA tem ganhado destaque na clínica cirúrgica por proporcionar analgesia, aumentar a circulação local, estimular a colagênese e reduzir edemas (JANSEN et al., 1989). ABOLAFIAet al. (1985), após avaliarem os efeitos da EA em feridas experimentalmente induzidas em ratos, verificaram que houve cicatrização cutânea mais precoce, sem presença de contaminação. Assim, objetivou-se, com este estudo, verificar os efeitos da estimulação por eletroacupuntura sobre os aspectos clínicos e de deambulação, no emprego do peritônio de bovino conservado em solução supersaturada de sal, para reparo tardio de lesões induzidas no tendão calcanear comum de coelhos.

\section{MATERIAL E MÉTODOS}

Para este estudo, foram utilizados 36 coelhos, mestiços, adultos jovens, sendo 18 machos e 18 fêmeas. Após serem submetidos a jejum alimentar e hídrico de seis horas, receberam maleato de acepromazina $^{\mathrm{a}}\left(0,5 \mathrm{mg} \mathrm{kg}^{-1}\right)$ por via intramuscular (IM). Administrou-se buprenorfina ${ }^{\mathrm{b}}\left(0,03 \mathrm{mg} \mathrm{kg}^{-1}\right)$ por via subcutânea (SC) e a anestesia foi realizada com cetamina $^{\mathrm{c}}\left(20 \mathrm{mg} \mathrm{kg}^{-1} \mathrm{IM}\right)$. Enrofloxacina ${ }^{\mathrm{d}}\left(10 \mathrm{mg} \mathrm{kg}^{-1}\right.$ IM) e cetoprofeno ${ }^{\mathrm{e}}\left(3,0 \mathrm{mg} \mathrm{kg}^{-1} \mathrm{IM}\right)$ foram administrados 45 minutos antes da intervenção cirúrgica.
Após incisão de pele na região lateral da tíbia direita, realizou-se a dissecação e exposição do tendão calcanear comum. Posteriormente, uma incisão de aproximadamente $1,0 \mathrm{~cm}$ foi feita no paratendão, expondo-se assim os tendões do músculo gastrocnêmico, do flexor digital superficial e as fibras musculares do grácil, semitendíneo e bíceps femoral. Com o tendão calcanear comum exposto, um ponto simples separado envolvendo todos seus componentes foi realizado a $1,0 \mathrm{~cm}$ distal à junção músculo-tendínea e a $1,0 \mathrm{~cm}$ cranial à junção ósteotendínea, com fio de náilon ${ }^{\mathrm{f}} 4-0$. Em seguida, o tendão foi seccionado, retirando-se um fragmento de $0,5 \mathrm{~cm}$. Ato contínuo, o tecido subcutâneo e a pele foram suturados como de rotina. Decorridos 30 dias desse procedimento, os coelhos passaram pelo mesmo préoperatório descrito anteriormente; contudo, a anestesia foi mantida com o halotano ${ }^{g}$, por meio de máscara nasooral vedada e circuito anestésico sem reinalação de gases, com fluxo de oxigênio de $200 \mathrm{~mL} \mathrm{~kg}^{-1}$ min. $\mathrm{O}$ acesso cirúrgico foi o mesmo realizado anteriormente para a secção do tendão. Entretanto, após a dissecação do tecido subcutâneo, introduziu-se um pino com rosca na articulação tíbio-társica, num ângulo de aproximadamente 60 graus, na direção póstero/anterior do tubérculo calcâneo e da tíbia. Ato contínuo, os cotos do tendão foram localizados, expostos e debridados. Um segmento de aproximadamente $2,5 \mathrm{~cm}$ do peritônio de bovino, preservado em solução supersaturada de sal $\left(1,5 \mathrm{~g}\right.$ de sal comercial ${ }^{\mathrm{h}}$ para $1 \mathrm{~mL}$ de água destilada) e já rehidratado por 30 minutos em solução salina ${ }^{i}$ a $0,9 \%$ acrescida de enrofloxacina a $0,1 \%$, foi enrolado, respeitando-se o sentido transversal das fibras, formando um tubo, fixado no seu terço médio por um ponto Wolff, com fio de náilon 4-0. Após isso, foi anastomosado às extremidades do tendão por meio de sutura de Bunnell, com fio náilon 4-0. O paratendão foi localizado e suturado com fio náilon 4-0 e ponto simples contínuo. O tecido subcutâneo e a pele foram suturados como de rotina.

No pós-operatório (PO), foi administrado, nos animais, enrofloxacina $\left(10 \mathrm{mg} \mathrm{kg}^{-1} \mathrm{SC}\right)$, durante sete dias, e buprenorfina $\left(0,03 \mathrm{mg} \mathrm{kg}^{-1} \mathrm{SC}\right)$, de $12 \mathrm{em} 12$ horas, durante três dias. Aplicou-se uma bandagem nãoaderente, não-compressiva, estendendo-se desde a articulação fêmuro-tíbio-patelar até a extremidade do membro operado. Os pontos de sutura de pele foram retirados decorridos 10 dias de PO. Os pinos intraarticulares foram removidos no $30^{\circ}$ dia de PO.

Os coelhos foram então distribuídos aleatoriamente em três grupos de igual número: grupo 
E10 - recebeu estímulo por eletroacupuntura a partir do segundo dia até o $11^{\circ}$ dia de PO da enxertia; grupo E20 - recebeu estímulo por eletroacupuntura a partir do $11^{\circ}$ dia até o $31^{\circ}$ dia de $\mathrm{PO}$ da enxertia; grupo C - não recebeu estímulo por eletroacupuntura durante o PO. Para o tratamento por eletroacupuntura, os animais do grupo E10 e E20 receberam aplicação de agulhas nos pontos E36, E41, B60, R3, F3 e VB34 (DRAEHMPAEHL \& ZOHMANN, 1997) no membro operado, e posterior estimulação elétrica, com corrente intermitente, na freqüência de $30 \mathrm{~Hz}$ e intensidade de 4-6 mA, diariamente, por 20 minutos, por meio do aparelho de eletroacupunturaj.

Para as avaliações clínicas, como presença de edema, hiperemia, secreção na região do enxerto e deiscência da sutura, o experimento foi dividido em três fases conforme a evolução: fase I - até o $11^{\circ}$ dia; fase II - do $12^{\circ}$ ao $31^{\circ}$ dia e fase III - do $32^{\circ}$ ao $91^{\circ}$ dia de PO. Também se avaliou a adaptação da deambulação, sendo esta estimada clinicamente, mediante quatro graus: grau I - animal não usa nem apóia o membro operado; grau II - uso não freqüente do membro operado durante estação e ao caminhar, não sustentando o peso no membro afetado; grau III - uso claudicante do membro na estação e ao caminhar, sustentando parcialmente o peso; grau IV - caminha sem claudicar e posiciona-se normalmente em estação.

Para a análise estatística, utilizou-se o teste de Wilcoxon, com nível de significância de $\mathrm{P}<0,05$. As medianas obtidas dos grupos em relação às variáveis grau, hiperemia e edema foram comparadas utilizandose o teste Kruskal-Wallis, com nível de significância de $\mathrm{P}<0,05$.

\section{RESULTADOS E DISCUSSÃO}

Não se observou, em nenhum dos animais deste estudo, deiscência de sutura e presença de secreção na área operada. Isto deveu-se provavelmente à eficiência da solução supersaturada de sal como meio conservante, mantendo o peritônio enxertado livre de contaminação, concordando com BRUN et al. (2002), os quais relataram que esta solução possui propriedade anti-séptica. Além disso, o uso do antibiótico enrofloxacina no pré-operatório deve ter diminuído a contaminação na ferida cirúrgica no transoperatório, além do seu uso por sete dias no pós-operatório, que preveniu uma possível infecção da ferida cirúrgica.

Os acupontos Zuzanli (E 36), Kunlun (B 60) e Yangligquan (VB 34) foram escolhidos em função de promoverem analgesia quando eletroestimulados. Segundo HAN et al. (1984), estes pontos, quando estimulados por uma freqüência baixa, como a utilizada neste experimento, promovem a liberação de betaendorfina e encefalina, que interagem com receptores mu e delta. Além disso, os pontos Kulun e Yangligquan são, segundo DRAEHMPAEHL \& ZOHMANN (1997), indicados para o tratamento de edemas na região da articulação tíbio-társica, por promoverem melhora da vascularização, ao ativarem, respectivamente, as artérias e veias safena e tibial cranial. Também o acuponto Zuzanli atua estimulando o nervo cutâneo lateral da sura, nervo este responsável pelo suprimento sensorial do tendão calcanear comum, causando, com isso, estímulo na atividade motora. Os pontos Taichong (F 3), Jiexi (E 41) e Taixi (R 3) foram utilizados por influenciarem, como descrito por DRAEHMPAEHL \& ZOHMANN (1997), a circulação e nutrição dos tendões do membro pélvico, como o tendão calcanear comum.

Nos animais do grupo estimulado a partir do segundo até o 11ํ dia de pós-operatório (PO) (E10), na fase I, não se encontrou presença de edema, concordando com o observado por LUNDEBERG et al. (1988), após utilizarem estimulação elétrica transcutânea no PO de cirurgia reconstrutiva da mama em mulheres, em que notaram redução do edema e da estase sangüínea. Essa ausência de edema observada nos coelhos do grupo E10 ocorreu devido à vasoconstrição na pele, causada pela ativação de alfareceptores pela eletroacupuntura (EA), como descrito por DRAEHMPAEHL \& ZOHMANN (1997). Além disso, segundo ZHAO \& ZHU (1990), a acupuntura pode ter efeitos diretos na liberação de mediadores do processo inflamatório, levando à redução da substância P. Essa substância, de acordo com SZABÓ \& BECHARA (2001), é a responsável pela liberação da histamina de mastócitos, com conseqüente indução de ardor e edema. Além disso, segundo BARROS (2001), a estimulação precoce após tenotomia por adjuvante da cicatrização diminui a quantidade de infiltrado inflamatório no local do reparo, diminuindo assim a inflamação. Já nos animais estimulados a partir do 11음 até o $31^{\circ}$ dia de PO (E20), verificou-se edema em grau leve no segundo e terceiro dias de PO. A partir do quarto até o nono dia, notou-se ausência de edema, voltando este a ser observado no $10^{\circ}$ e no $11^{\circ}$ dia. Isso deveu-se provavelmente ao não uso da EA durante este período neste grupo, ocorrendo assim o processo inflamatório comumente observado no PO, oriundo do trauma tecidual. Segundo AUTEFAGE (1999); GIGANTE et al. (1996), este período de inflamação dura cerca de um a sete dias, com presença de edema devido à liberação de histamina. Este fato também foi observado nos animais do grupo não-estimulado (grupo C), nos quais se encontrou presença de edema em grau moderado durante a fase 1. Entretanto, tanto para os coelhos do 
grupo E20 quanto para o C, esse edema diminuiu com o decorrer dos dias, coincidindo com o término da fase inflamatória.

Na fase II, também não se observou edema nos animais do grupo E10, discordando do resultado achado por REZENDE et al. (2001), após implantarem polímero de mamona no tendão calcanear comum de coelhos, em que observaram edema local por três semanas no PO. A ausência de edema nos membros dos animais do grupo E10, observado neste trabalho, ocorreu devido à eficácia da EA no controle desta alteração. Nos coelhos do grupo E20, encontrou-se edema de grau moderado, até o 16으 dia após a enxertia, semelhante ao observado no grupo C. A partir do $17^{\circ}$ dia de PO, o edema encontrado era de grau leve, que foi reduzindo com o decorrer dos dias. Essa redução do edema observada nos animais do grupo E20 deveuse à ação antiinflamatória da EA, fato também relatado por KENDALL (1989), ao utilizar acupuntura no pavilhão auricular inflamado de coelhos, no qual observou diminuição da inflamação. Esta observação discorda de TEIXEIRA (2001), o qual relatou que a introdução das agulhas nos acupontos produz a liberação de substâncias inflamatórias, o que induz a formação do edema. Nos animais do grupo C, esse edema era moderado até o $30^{\circ}$ dia do procedimento cirúrgico, não havendo diferença estatística entre os dias. Isto provavelmente deveu-se à imobilização rígida da articulação tíbio-társica aplicada neste período, que pode ter proporcionado uma estase linfática, semelhante ao relatado por GREGA et al. (2003), após enxertarem submucosa de intestino delgado em tendão calcanear de coelhos, no qual observaram inflamação aguda até o $30^{\circ}$ dia de PO. Entretanto, nos animais deste estudo, observou-se diminuição do edema com o decorrer dos dias. Em todos os animais, não se encontrou edema a partir do $31^{\circ}$ dia da enxertia, devido ao fato de, neste período, os animais não estarem com a imobilização rígida na articulação tíbio-társica, que foi removida aos 30 dias de PO. Além disso, neste período, segundo GIGANTE et al. (1996), a ferida tendínea está na fase de remodelação, que é marcada pela redução de número de células inflamatórias e retorno da vascularização.

$\mathrm{Na}$ fase I, nos animais do grupo E10, observou-se, somente no segundo dia do enxerto, hiperemia de grau leve, a qual regrediu nos dias subseqüentes, concordando com os achados de TATARUNAS et al. (1998), após utilizarem o laser arseneto de gálio em terapia única no PO de feridas cutâneas de gatas. Entretanto, TEIXEIRA (2001) comenta que a acupuntura induz a uma inflamação asséptica, com conseqüente produção de hiperemia, fato este não observado neste estudo. Nos coelhos do grupo E20, a hiperemia no membro operado apresentava-se em grau moderado, semelhante aos do grupo C. Esta observação se deve aos animais não estarem, neste período, recebendo estímulo pela EA, pois, segundo DRAEHMPAEHL \& ZOHMANN (1997), o estímulo elétrico causa movimentação da pele e da musculatura, que aumenta o fluxo linfático e sangüíneo, causando assim aumento na vascularização e melhora na estase sangüínea. $\mathrm{Na}$ fase II, não se encontrou hiperemia nos coelhos do E10, coincidindo com o observado por GAN et al. (1995), que verificaram que a estimulação precoce no tendão flexor de galinhas com ultra-som terapêutico diminuiu o processo inflamatório, melhorando a vascularização tecidual. Já nos animais do E20, notou-se grau moderado de hiperemia do $11^{\circ}$ até o 17 o dia de PO, que diminuiu com o decorrer dos dias. A moderada hiperemia encontrada neste período deveu-se à alta reação vascular, que de acordo com EARLEY (1981), nesta fase alcança seu pico máximo. A redução da hiperemia observada a partir do 17ํ dia da enxertia ocorreu provavelmente devido à ação da EA, pois esta, segundo DRAEHMPAEHL \& ZOHMANN (1997), causa vasoconstrição na pele, reduzindo conseqüentemente o seu rubor. Este fato, contudo, não foi observado nos animais do grupo $\mathrm{C}$, onde encontrouse hiperemia de grau moderado até o $29^{\circ}$ dia de PO. A partir do $31^{\circ}$ dia de $\mathrm{PO}$, não se observou hiperemia em nenhum dos animais.

Verificou-se, em todos os animais, após o final do procedimento cirúrgico de enxertia e de recuperação da anestesia, que estes apoiavam com cautela a face plantar do membro operado. Isso ocorreu provavelmente devido ao uso no pré-operatório do analgésico, que aliviou a dor. Fato este semelhante ao encontrado por REZENDE et al. (2001), após substituir parcialmente o tendão calcanear comum de coelhos por uma prótese de polímero de mamona. Não se observou diferença significativa entre os grupos em relação ao grau de deambulação em nenhuma fase do PO. Este resultado deveu-se ao uso de imobilização com pino intra-articular por 30 dias no PO, que promoveu, em todos os animais, uma restrição locomotora, que, segundo RAISER (2000), é imprescindível para que o tendão lesado receba suprimento vascular e forme mínima cicatriz. Este resultado foi também observado por MAZZANTI et al. (2004), ao utilizarem o laser de arseneto de gálio, por 10 dias, no PO de homoimplante ortotópico para reparo tenopatelar em cães. Contudo, nos animais do E10 e E20, houve uma melhora no padrão deambulatório mais precoce (Figuras 1 e 2) quando comparado ao grupo C 


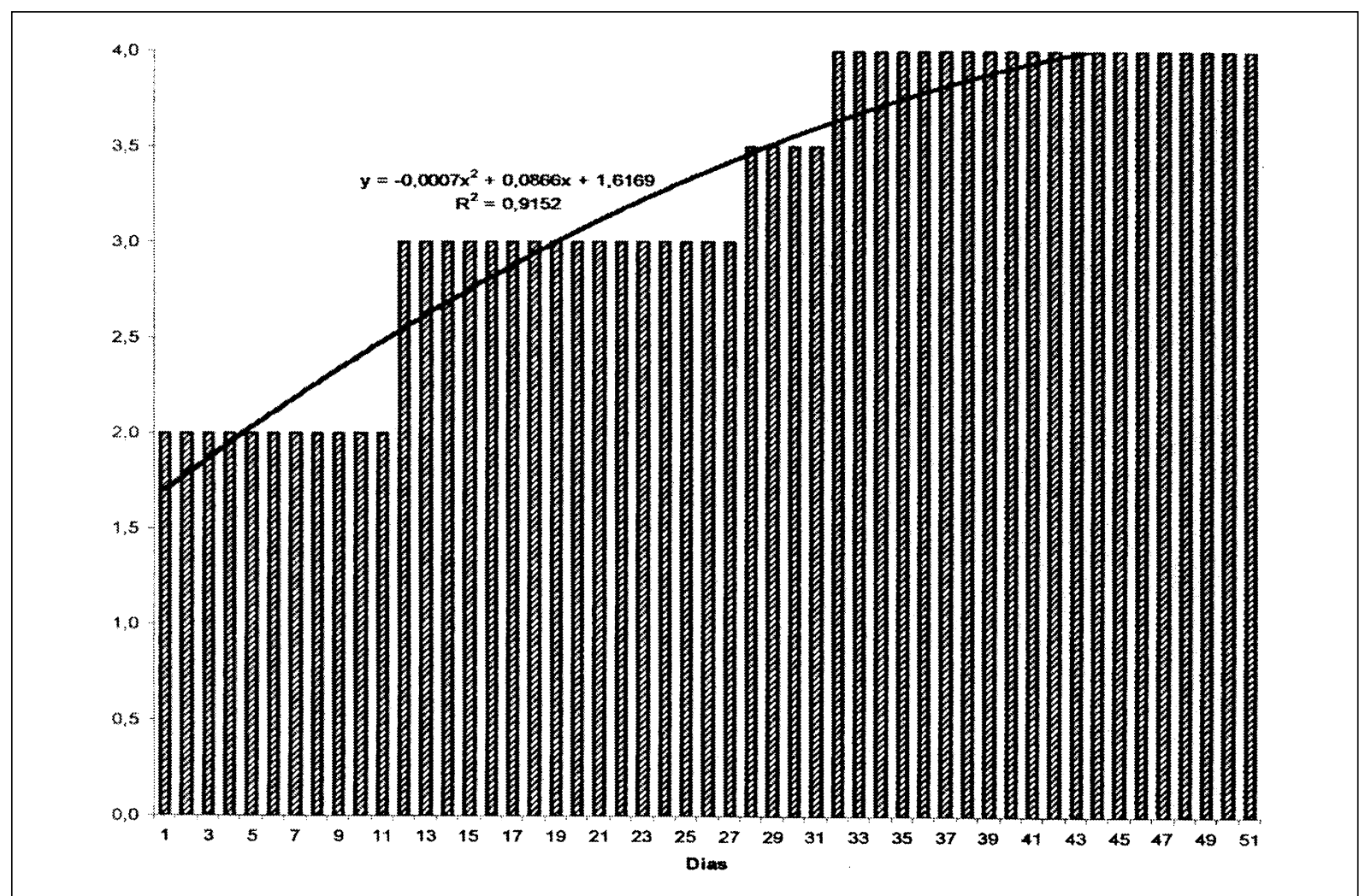

Figura 1 - Histograma com linha e equação de regressão do grau de deambulação observado no membro pélvico direito de coelhos submetidos a enxerto do tendão calcanear comum com peritônio bovino tratado pela eletroacupuntura do segundo ao $11^{\circ}$ dia de pós-operatório (grupo E10).

(Figura 3). Provavelmente, isto deveu-se à analgesia proporcionada pelo uso da EA, pois, segundo HAN et al. (1984), o estímulo de baixa freqüência, como o usado neste experimento, produz analgesia cumulativa após 10 a 20 minutos do estímulo, por liberar beta-endorfinas e encefalina, que interagem com receptores mu e delta. Além disso, de acordo com DRAEHMPAEHL \& ZOHMANN (1997), a EA tonifica a musculatura e melhora a contração muscular, fato que pode ter colaborado para o retorno antecipado da deambulação nos animais do E10 e E20. Após o dia 51 de PO, não se notou, em nenhum animal, sinal de claudicação, fato semelhante ao observado por RAISER et al. (2001), que encontraram deambulação normal aos 44 dias de PO de aloimplante ortotópico de tendão calcanear comum em cães. Estes fatos deveram-se à resistência do tecido enxertado, que, neste período, suportou o estresse aplicado sobre ele. De acordo com AUTEFAGE (1999), nesta fase, a resistência de um tendão seccionado é de $56 \%$ de um tendão íntegro, que é o suficiente para suportar a contração fisiológica. Entretanto, na condição de um enxerto, por possuir duas áreas de anastomose e um segmento de substituição, essa resistência talvez seja inferior.

\section{CONCLUSÃO}

Nas condições deste trabalho, pôde-se concluir que a utilização da eletroacupuntura na fase precoce da cicatrização do tendão calcanear comum de coelhos, após reparo tardio com peritônio de bovino, impede a formação de edema e hiperemia no membro e que o tratamento com eletroacupuntura no pósoperatório não melhora o desempenho da deambulação.

\section{FONTES DE AQUISIÇÃO}

a.Acepram $1 \%$. Univet.

b.Temgesic. Schering-Plough.

c.Ketamina $10 \%$. Fort-Dodge.

d.Flotril 5\%. Schering-Plough.

e.Ketofen. Merial.

f.Náilon monofilamentoso. Brasmédica Indústria Farmacêutica. g.Halothane. Laboratórios Ayerst.

h.Sal Cisne refinado. Cabo Frio.

i.Solução fisiológica de cloreto de sódio a 0,9\%. Halex Istar. j.Multiple eletronic acupunctoscope. WQ - IOD1.

Ciência Rural, v.36, n.6, nov-dez, 2006. 


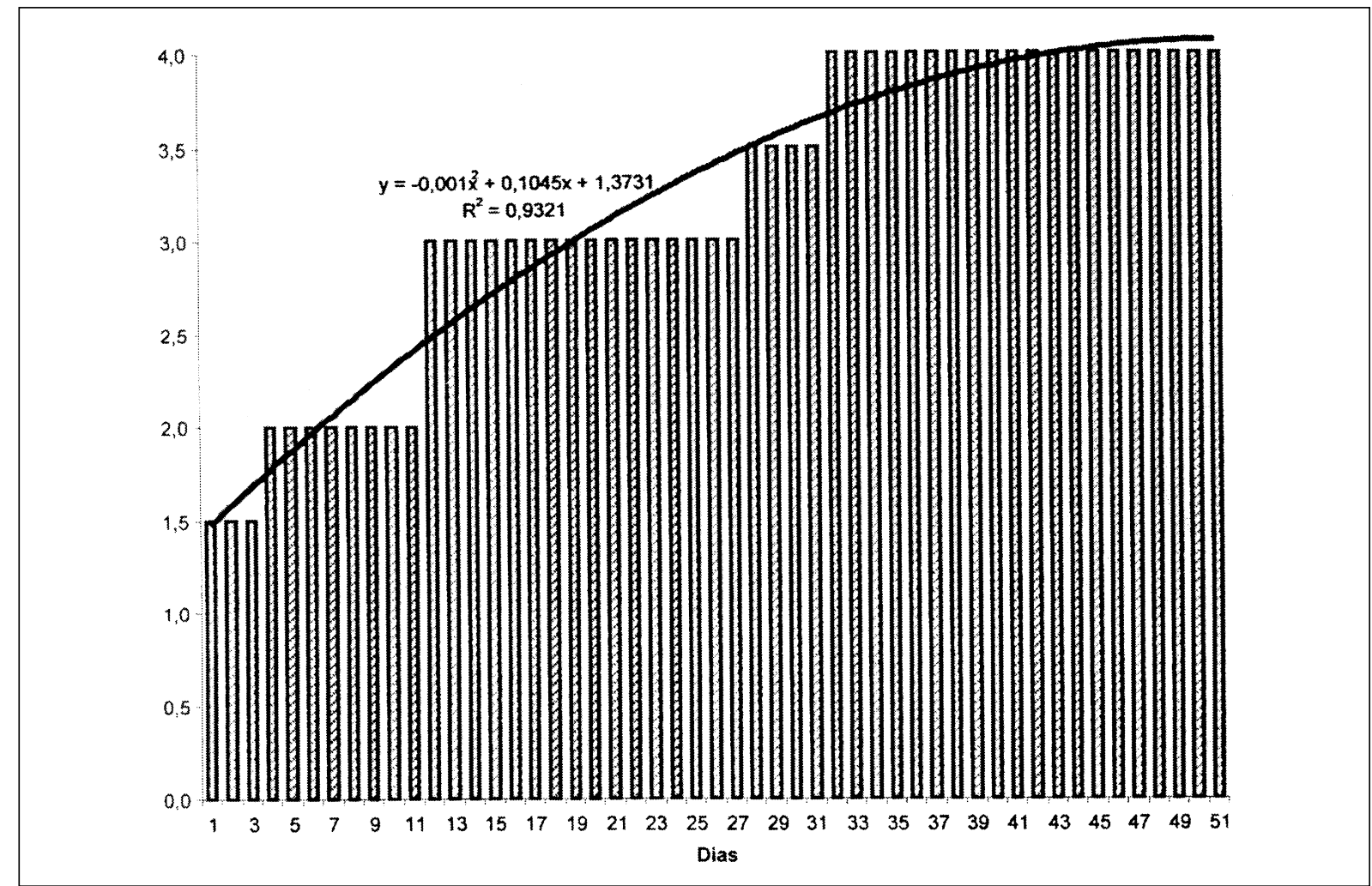

Figura 2 - Histograma com linha e equação de regressão do grau de deambulação observado no membro pélvico direito de coelhos submetidos a enxerto do tendão calcanear comum com peritônio bovino tratado pela eletroacupuntura do $11^{\circ}$ ao $31^{\circ}$ dia de pós-operatório (grupo E20).

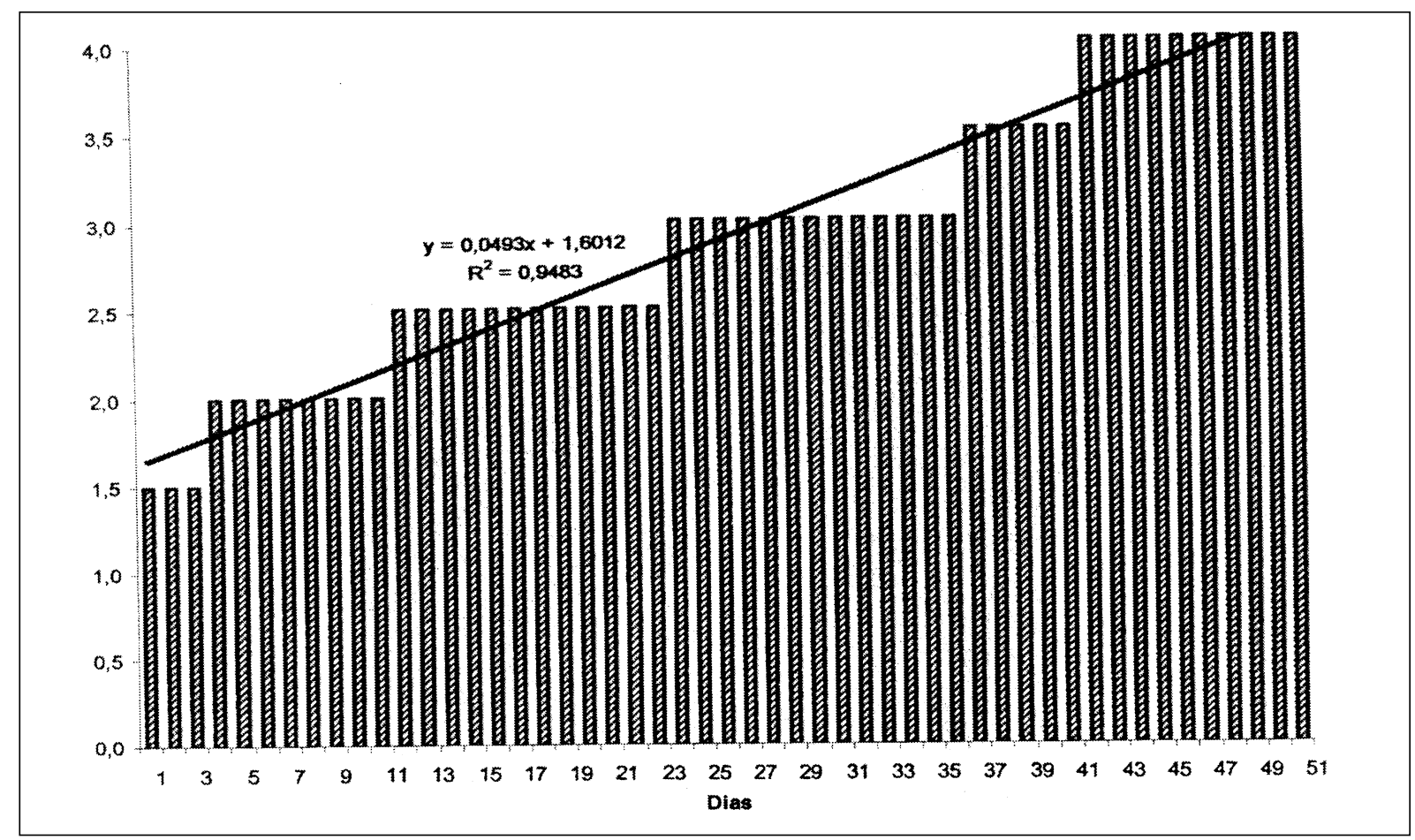

Figura 3 - Histograma com linha e equação de regressão do grau de deambulação observado no membro pélvico direito de coelhos submetidos a enxerto do tendão calcanear com peritônio bovino não-tratado pela eletroacupuntura no pós-operatório (grupo C). 


\section{REFERÊNCIAS}

ABOLAFIA, A.J.A. et al. Evaluación del efecto cicatrizante de la acupuntura. Veterinária México, Coyoacán, v.16, p.2731,1985 .

ARON, D.N. Tendões. In: BOJRAB, M.J. Técnicas atuais em cirurgia de pequenos animais. São Paulo: Roca, 1996. Cap.5, p.516-527.

AUTEFAGE, A. La cicatrizazzione dei tendini e dei ligamenti. Summa, Buenos Aires, v.16, n.1, p.29-34, 1999.

BARROS, J.R. Os efeitos do ultra-som na cicatrização de tendões flexores de coelho após tenorrafia. 2001. $57 \mathrm{f}$. Dissertação (Mestrado em Bioengenharia) - Universidade de São Paulo, Ribeirão Preto.

BRUN, M.V. et al. Solução hipersaturada de sal como conservante de pericárdio canino utilizado na reparação do músculo reto abdominal de ratos wistar. Ciência Rural, Santa Maria, v.32, n.6, p.1019-1025, 2002.

CLARCK, D.M. Tendon injury and repair. In: BOJRAB, M.J. Disease mechanisms in small animal surgery. Philadelphia: Lee \& Febiger, 1993. Cap.142, p.1079-1082.

COSTA NETO, J.M.C. et al. Tenoplastia experimental do calcâneo em cães com peritônio bovino conservado em glicerina. Ciência Rural, Santa Maria, v 29, n.4, p.697-703, 1999.

DRAEHMPAEHL, D.; ZOHMANN, A. Acupuntura na cão e no gato. Princípios básicos e prática científica. São Paulo: Roca, 1997. 245p.

EARLEY, T.D. Tendon discords. In: BOJRAB, M.J. Pathophysiology in small animal surgery. Philadelphia: Lea \& Febiger, 1981. Cap.8, p.851-866.

GAN, B.S. et al. The effects of ultrasound treatment on flexor tendon healing in the chicken limb. Journal of Hand Surgery, Leeds, v.20, n.6, p.809-814, 1995.

GIGANTE, A. Fibrillogenesis in tendon healing: a experimental study. Bolettino Societa Italiana Biologia Sperimentali, Napoli, v.7-8, n.72, p.203-210, 1996.

GREGA, F.H. et al. Interposição de submucosa de intestino delgado para reparo de tendão em coelhos. Acta Cirúrgica Brasileira, São Paulo, v.18, supl., p.14, 2003.

GUM, S.L.B.S. et al. Combined ultrasound, electrical stimulation, and laser promote collagen synthesis with moderate changes in tendon biomechanics. American Journal of Physical Medicine and Rehabilitation, Indianápolis, v.76, n.4, p.288296, 1997.

HAN, J.S. et al. High and low frequency electroacupuncture analgesia are mediated by different opioid peptides. Pain, São Francisco, v.2, supl., p.543, 1984.

JANSEN, D. et al. Acupuncture and sensory neuropeptides increase cutaneous blood flow in rats. Neuroscience Letters, San Diego, v.97, p.305-309, 1989.
KENDALL, D.E. A scientific model for acupuncture. Part I. American Journal of Acupuncture, Califórnia, v.17, n.3, p.251-268, 1989.

LUNDEBERG, T. et al. Effect of electrical nerve stimulation on healing of ischaemic skin flaps. The Lancet, Oxford, v.24, p.712-714, 1988.

MADDEN, J.W. Current concepts of wound healing as applied to hand surgery. Orthopedic of Clinics North American, New York, v.1, n.2, p.325-334, 1970.

MAZZANTI, A. et al. Homoimplante ortotópico conservado, associado à terapia "soft laser" na reparação tenopatelar em cão. Ciência Rural, Santa Maria, v.34, n.2, p.429- 437, 2004.

PAYNE, J.T.; TOMLINSOM, J.L. Composition, structure, and function of muscle, tendon and ligament. In: BOJRAB, M.J. Disease mechanisms in small animal surgery. Philadelphia: Lea \& Febiber, 1993. Cap.95, p.656-662.

RAISER, A.G. Homoimplante ortotópico de tendão calcâneo comum, preservado em glicerina a $98 \%$ e tratado com radiação laser arseneto de gálio, em cães. 2000. 80f. Tese (Doutorado em Cirurgia) - Universidade Federal de Santa Maria, Santa Maria.

RAISER, A.G. et al. Aloimplante ortotópico de tendão calcanear comum conservado em glicerina a $98 \%$ em cães. Influência da imobilização e da radiação laser arsenato de gálio. Ciência Rural, Santa Maria, v.7, n.1, p.21-31, 2001.

REZENDE, C.M.F. et al. Estudo experimental do poliuretano de óleo de mamona (Ricinus communis) como substituto parcial do tendão calcâneo comum em coelhos (Oryctolagus cuniculus). Arquivo Brasileiro de Medicina Veterinária e Zootecnia, Belo Horizonte, v.53, n.6, p.695-670, 2001.

SZABÓ, M.V.R.S.; BECHARA, G.H. Acupuntura: bases científicas e aplicações. Ciência Rural, Santa Maria, v.31, n.6, p.1091-1099, 2001

TATARUNAS, A.C. et al. Estudo clínico e anatomopatológico da cicatrização cutânea no gato doméstico: utilização do laser de baixa potência GaAs (904 nm). Acta Cir Bras, v.13, n.2, 1998. Cited 06 Jun 2006. Online. Available from World Wide Web:http://www.scielo.br/scielo.php?script=sci_arttext\&pid= S010286501998000200004\&lng=en\&nrm=iso>. ISSN 01028650 .

TEIXEIRA, M.J. Fisiopatologia da dor neuropática. In: ANDRADE FILHO, A.C.C. Dor diagnóstico e tratamento. São Paulo: Roca, 2001. Cap.2, p.7-42.

WANG, D.E. Tendon repair. Journal of Hand Thermal, Lund, v.11, n.2, p.105-110, 1998.

ZHAO, F.; ZHU, L. Terapeutic effects of acupuntcture on acute experimental arthritis in rats. Chen Tzu Yen Chiu, Wuhan, v.5, n.3, p.197-202, 1990. 